\title{
Perú, un imaginario inconcluso; una reflexión desde los trabajos de Matos Mar a la coyuntura actual
}

\author{
Peru, an unfinished imaginary; a reflection from the work of Matos \\ Mar about the current situation
}

\section{Peru, um imaginário inacabado; uma reflexão da obra de Matos Mar à situação atual}

\author{
Flavio Marino Ramirez Cornelio \\ Universidad Nacional Mayor de San Marcos \\ flavio.ramirez@unmsm.edu.pe \\ https://orcid.org/0000-0002-8742-1136
}

\author{
Desborde popular y crisis del Estado: el nuevo rostro del \\ Perú en la década de 1980 \\ Autor: José Matos Mar \\ Editorial: IEP Ediciones \\ Año de Edición: 1986
}

\section{RESUMEN}

La actual crisis política del Perú nos lleva a preguntar de alguna manera cómo es que se suscitaron los problemas que atravesamos. Si hablamos de un problema coyuntural propio de las elecciones presidenciales o si realmente estamos hablando de un problema estructural que nos compete como sociedad y cuyos síntomas latentes se muestran cada cinco años. Matos Mar nos explica como las migraciones marcan un antes y un después sobre el imaginario que construimos sobre el Perú, o si es que acaso existen muchos. Este es un trabajo antropológico y sociológico que nos trata de explicar acerca del origen de las barriadas en los márgenes de la Lima actual y

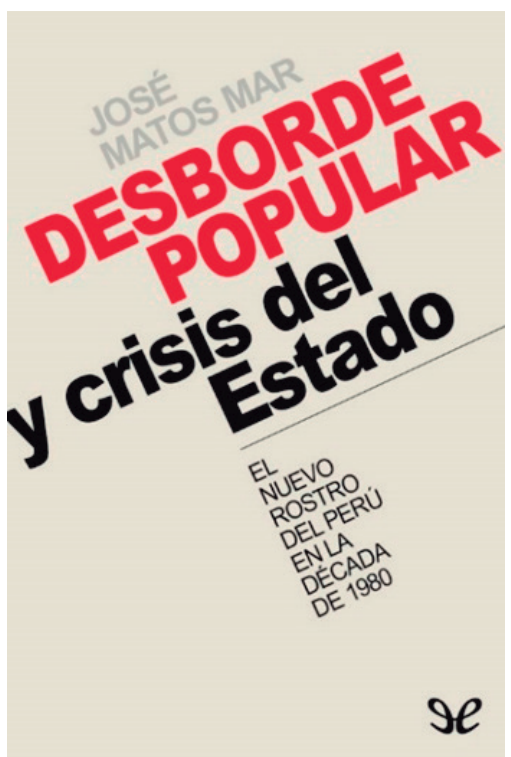
como esto reconfiguraron el escenario socio político del Perú y a su vez como el estado en su incapacidad de resolver las demandas sociales y económicas de esta nueva reconfiguración social se origina un nuevo fenómeno social y económico que padecemos hasta nuestros días, la informalidad.

\section{ABSTRACT}

The current political crisis in Peru leads us to ask in some way how the problems we are going through arose. If we are talking about a temporary problem typical of the presidential elections or if we are really

Ramirez, F. (2021). Perú, un imaginario inconcluso; una reflexión desde los trabajos de Matos Mar a la coyuntura actual. Espiral, revista de geografías y ciencias sociales, 3(5), 109-115. https://dx.doi.org/10.15381/espiral.v3i5.21181 
talking about a structural problem that concerns us as a society and whose latent symptoms appear every five years. Matos Mar will explain to us how migrations mark a before and after on the imaginary that we build about Peru, or if there are many. This is an anthropological and sociological work that will try to explain us about the origin of the neighborhoods on the margins of current Lima and how this reconfigured the socio-political scenario of Peru and in turn as the state in its inability to resolve social economic demands From this new social reconfiguration originates a new social and economic phenomenon that we suffer to this day, informality.

\section{RESUMO}

A atual crise política no Peru nos leva a perguntar de alguma forma como surgiram os problemas que vivemos. Se estamos falando de um problema conjuntural típico das eleições presidenciais ou se estamos realmente falando de um problema estrutural que nos diz respeito como sociedade e cujos sintomas latentes aparecem a cada cinco anos. Matos Mar nos explicará como as migrações marcam um antes e um depois no imaginário que construímos sobre o Peru, ou se são muitos. Este é um trabalho antropológico e sociológico que tentará nos explicar sobre a origem dos bairros nas margens da Lima atual e como isso reconfigurou o cenário sócio-político do Peru e, por sua vez, como o Estado padece de uma incapacidade de resolução social e demandas sociais econômicas. Desta nova reconfiguração social nasce um novo fenômeno social e econômico que sofremos até hoje, a informalidade.

PALABRAS CLAVE: Estado; informalidad; crisis social; migración; movilidad social.

KEYWORDS: State; informality; social crisis; migration; social mobility

PALAVRAS-CHAVE: Estado; informalidade; crise social; migração; mobilidade social

Crisis social. Es lo que actualmente se viene aconteciendo en el Perú del bicentenario. Pero vayamos un poco más allá. ¿Estamos atravesando acaso una crisis coyuntural o podríamos estar hablando de una problemática estructural? Está claro que en la actualidad el Perú llega a sus doscientos años en profundas convulsiones en todas las áreas sociales que se puedan señalar, por ejemplo; en el sector económico, sanitario, político y hasta en las relaciones interpersonales debido a la última gran polarización ideológica producto de las últimas elecciones presidenciales. Durante muchos años, lamentablemente, Perú se encuentra incesablemente en constantes desbordes sociales.

Tratar de entender la actualidad parte de saber cómo es que llegamos a ella y en ese sentido repensar sobre el notable trabajo que realizó José Matos Mar hace poco menos de cuarenta años atrás resulta imperativo para nuestros intereses.

Primero adentrémonos un poco a las circunstancias de quien en vida fue José Matos Mar, uno de los fundadores de la disciplina antropológica en nuestro país. Si hablamos de Eduardo Valcárcel cómo el fundador impulsor de esta ciencia, José Matos Mar fue de los principales personajes que logró institucionalizarla y darle la importancia debida en nuestra, para ya entonces, resquebrajada sociedad.

Los estudios por las ciencias sociales no puede dejar pasar por alto el nombre de José Matos Mar, quién en vida fuera (1921 - 2015), uno de los mayores impulsores de la institucionalización de la antropología en la academia peruana. Durante el transcurso de este tratado caracterizaremos a nuestro autor y su trabajo, mediante la formulación de preguntas y el desarrollo de sus principales conceptos. José Matos Mar, incansable buscador de conocimiento, no solo exploró en el campo de la antropología, sino también product de esa curiosidad incursionó en los campos de la arqueología, historia, entre otros. De ahí su vínculo académico con varios intelectuales de estas ciencias del conocimiento, tales como Julio C. Tello o Raúl Porras Barnechea.

Como incansable investigador e impulsor de innumerables proyectos, él conjunto a grandes nombres de la ciencia como; María Rostworowski, Aníbal Quijano, Alberto Escobar, Augusto Salazar Bondy, Jorge Bravo Bresani, Jorge González, José María Arguedas y John V. Murra deciden fundar el Instituto de Estudios Peruanos (IEP) el 
año 1964. Pero este proyecto no sería su único reconocimiento por alcanzar expandir esta disciplina, sino que también recordamos, algunos años atrás, entre 1940 y 1950, junto a Luis Eduardo Valcárcel, en la fundación del Instituto de Etnología y Arqueología en San Marcos y posteriormente con el Museo de la Cultura Peruana.

José Matos Mar fue de los más notables y destacados estudiosos de la disciplina antropológica y podemos mencionar con mucha certeza que uno de sus mayores logros fue abordar la problemática urbana en una academia en donde se priorizaba a la antropología en el ámbito rural, tradicionalmente estudiando "al otro" de "culturas diferentes y alejadas". Se puede decir que Matos Mar logra ampliar la cancha tradicional de la antropología y sus estudios en el campo urbano permitieron a las ciencias sociales y antropológicas abordar y complejizar su objeto de estudio. Es entonces cuando desde una mirada antropológica, con total relevancia para las ciencias sociales, se comienza a ver los distintos fenómenos socio culturales en el espacio urbano de las polis occidentales costeñas -en este caso- desde Lima durante el siglo pasado.

En relación con los estudios acerca del fenómeno de las migraciones, desde el apartado rural a las polis costeñas, visto en su sentido más restringido, Matos Mar fue el pionero y sin lugar a dudas reconfiguró los conceptos tradicionales sobre la disciplina antropológica. Teoría que nos podrá permitir entender la situación actual del Perú del bicentenario, sus problemas y sus posibles soluciones.

Rural, urbano; andino, europeo; indio, criollo; atraso, modernidad. Son ejemplos de categorías contrapuestas que Matos Mar estudió con mucho detalle, que buscó explicar y dar sentido a cómo lo hispano - europeo desplazó a la cultura andina y la minimizó con un carácter dominante formando así una nueva estructura social y política, de la cual pareciera que no nos hemos librado hasta nuestros días. Este sincretismo y/o conflicto que se evidencia al encontrarse "dos mundos" o en referencia a Matos Mar - un estado colonial y el resto de la sociedad- determina una "nación inconclusa", la cual al mismo tiempo es producto de las constantes oleadas migratorias, llegando estas a ser consideradas un fenómeno "hito" en la historia del Perú. Para Matos Mar las oleadas migratorias, principalmente del siglo XX. constituyen un momento relevante para nuestra sociedad, ya que producto de estas se origina una nueva organización colectiva, un nuevo imaginario de nación, se gesta las condiciones para la informalidad y sus consecuencias; en síntesis, podríamos mencionar que se origina, lo que él llamaría; un desborde popular y la crisis del estado, al no poder -o quererconcluir estas necesidades.

Esta notable obra de las ciencias sociales cuenta con tres ediciones que fueron lanzadas al mercado por primera vez en el año 1984, y así consecutivamente, hasta 1986. "Desborde popular y crisis del estado" fue considerada un éxito en ventas y aún veinte años después se lanzó otra edición especial, realizando un balance sobre los acontecimientos ocurridos, revelándonos que el propósito del libro mucho tiempo después, aún mantienen vigencia sobre un escenario peruano mucho más complejo de entender, y como una de sus respectivas consecuencias, la de gobernar. Esta última edición (año 2004) cuenta con el texto original de Matos Mar cuyo propósito nos comentaba era acerca de cómo un desborde de carácter institucional producto del hito histórico que él consideraba, las migraciones, no solo encontraba en un reconfigurado espacio geográfico socio cultural "urbano" a las personas, sino también que, con ellas, nuevas formas de estilo de vida y costumbres, complejizando así una nueva organización social y como consecuencia construyendo un "nuevo rostro" del Perú. Necesariamente el paso del tiempo llevó a actualizar dicha información, ya que veinte años después el escenario social y político era otro. Si bien temas como el retorno a la democracia, la crisis económica y la expansión de terrorismo del campo a la capital marcaban los años ochenta, ahora la realidad marcaba una evolución socio 
cultural con características propias al tiempo histórico. Definitivamente se acertó en su momento de realizar una mirada veinte años después.

Matos Mar nos habla sobre un "Legado andino y patria criolla", una nación inconclusa y comienza contextualizando cuál fue el panorama social siglos atrás, en dónde Lima recibe la llegada de miles de personas provenientes de los andes peruanos, muchos de ellos campesinos - ganaderos y con ellos sus linajes. El siglo XVI fue uno de los años más importantes debido a que marcaría un cambio significativo sobre el devenir histórico de lo que hoy llamamos Perú. Un suceso claramente conocido por todos cambiaría el rumbo de nuestra historia, o, mejor dicho, originaría la misma. La exclusividad de lo indígena se perdería y la colonización traería consigo la formación de una "patria criolla" la cual poseída de aspectos culturales "superiores" generaría una relación de poder sometiendo exclusivamente a lo "indígena", iniciando un proceso de marginación que se puede evidenciar hasta nuestros días.

Es así como se evidencia la génesis de una persistente discriminación entre lo "serrano - costeño", "indio - criollo", "rural - urbano", etc. relación de sometimiento y dominación en base a cierto distanciamiento social y cultural impuesto entre lo que Golte llamaría como: sistema bicultural (Golte, 2001). O lo que en este caso Matos Mar refiere y ejemplifica como Estado colonial y el resto de la sociedad.

Matos Mar trata de narrar mediante una perspectiva histórica cómo es que la economía del Perú se refleja mediante los empréstitos e inversiones inglesas que desarrollaron los enclaves de azúcar y haciendas algodoneras; el trabajo sobre el petróleo y la incursión con el caucho, emergiendo nuevos grupos de poder, exclusivamente herencia de un estado colonial manteniendo una subordinación y relación de dominio con el indígena.

Es por entonces, más o menos entre 1885 y 1920, que la propiedad monopólica se extiende abusivamente en el agro, la minería y la industria urbana y con ello aparecen en las ciudades de la costa los obreros asalariados y en las áreas ocupadas por el capital monopólico los campesinos indígenas son arrancados, por el enganche, de sus comunidades y expuestos a una nueva relación social y cultural. (Matos Mar, 1980, p: 28)

Es así como en la literatura de Matos Mar nos señala que los indígenas son llevados al límite y obligados a migrar por efectos de la concentración de la propiedad de la tierra. Mientras que en su contraparte en las urbes el aparataje obrero quién también sufre sometimiento ya no solo de origen étnico, sino también de clase; empiezan a ser influenciado por ideologías anarquistas llegando a un momento de asimilación de un análisis diferente de la sociedad peruana y la realidad social en la cual están enmarcados.

La década de 1920 es un momento de estabilidad de ideologías, de análisis de la realidad nacional, de modernización del país, del camino en búsqueda de un EstadoNación. El problema de los legados y las cuestiones de nación e identidad se revelaron a partir del año de 1980, de forma más apremiantes que nunca. Las reformas del general Velasco Alvarado no consiguieron iniciar la integración, pero habían creado las condiciones para una poderosa liberación en el mundo andino y con ellos también los sectores populares urbanos.

Para entonces se hace evidente la relación interseccional y el análisis histórico acerca del enfrentamiento y las relaciones sociales asimétricas que se han desarrollado entre distintos grupos sociales o si se quiere mencionar; segmentos, o dos partes de este imaginario del Perú, para luego ser analiazadas mediante la categoría de clase y su interrelación con lo étnico, y como esto se evidencia aún más con la constante relación entre estos dos grandes apartados de un mismo Perú; uno "oficial" y otro 
"real", mientras se desarrollan distintas variables que responden a este fenómeno, tanto como; la dominación política, explotación económica y discriminación étnica.

Matos Mar con el fin de conseguir su objetivo nos da a notar lo determinante que resulta la historia del Perú, queriendo encontrar en esta la génesis del momento por el cual atravesamos. Nos señala con claridad, y como ya mencionamos, la existencia de un Perú "oficial" de un carácter dominante, impositivo e improvisto de empatía social a espaldas al pueblo, a lo "popular", a su cultura, tradiciones, emociones, sus subjetividades, etc. Y nos señala también otra realidad, un Perú "real", el de las mayorías, el auténtico, el de la resistencia en todo sentido de la palabra. Se evidencia entonces una enorme brecha social entre los dominadores y los dominados. Es en este apartado donde se resalta lo innovador de Matos Mar quién trata de reconstruir la historia nacional exhibiendo la transformación que han sido sujetos, tanto de un lado como del otro, señalando la resistencia e incluso la integración de las mismas y sus consecuencias.

Es en la década de 1980 en dónde Matos nos señala que los cambios sociales que se gestaron muchas décadas atrás se tornaron cada vez más agudas. Para entonces las problemáticas sociales se concentraron y se desencadenaron sobre una sociedad que ya atravesaba una profunda crisis producto del conflicto armado interno, una profunda crisis económica y diversos problemas sociales que acrecentó la brecha de desigualdad, con esto se imposibilitó un fortalecimiento de la democracia que venía golpeada por años de dictadura militar. Posteriormente se indicaría que la falta de unidad como nación y de un proyecto que construya una identidad homogénea serían factores vitales para las crisis del Perú republicano, siendo este un problema no resuelto "al no haberse encontrado una fórmula de síntesis ecuánime que forjase un continuo entre la herencia andina y la herencia colonial, la deuda histórica del siglo XIX deviene en tarea prioritaria para el Perú del siglo XXI" (Matos Mar, 1988).

Matos Mar señala una crisis económica nacional, producto de la subordinación al sistema financiero. En muestra de solución por parte del estado ante esta crisis fue el incremento del control burocrático sobre los sectores económicos de la industria, comercio y trabajo, ocasionando la formación de un estado mucho más infructífero y alejado de un sector de la sociedad. Frente a esta situación, estos sectores económicos deciden alejarse (o los alejan) hacia los márgenes de la legalidad, originando de esta forma una economía distante de la "oficial", una economía "informal".

Para entonces desborde popular y la crisis del estado nos revela, como ya lo mencionamos, la existencia de dos lados del Perú; uno formal u "oficial" caracterizado por la presencia del estado con una naturaleza centralista, una fuerte presencia y hegemonía de partidos políticos tradicionales y en el sector económico político y social bajo un régimen burocrático inoperante. Este Perú se desenvuelve en las grandes ciudades, sobre todo Lima centro privilegiado por el Perú "oficial". Diferente situación convive en el otro lado del Perú "informal", cuyo impulso, desarrollo y maltrato se desenvuelve en las regiones y en las periferias de las grandes ciudades. Este Perú "informal" representa este sector social marginado, apartado, visto pero sin querer verlo, cuyo contraste es heredado de la época colonial. El Perú de esta época (1984) es un espacio de relaciones sociales y jerárquicas de dominio, sometimiento de donde surge con fuerza un sector contestatario pretendiendo balancear por sus medios el equilibrio de fuerzas de las instituciones oficiales que concentran el poder económico, esto producto de la inoperancia de la misma para con las necesidades de este Perú "informal". Matos Mar señala que el otro Perú "oficial" no podrá volver a poner otra vez sus condiciones ante las nuevas instituciones emergentes que produce el Perú informal.

En este sentido observamos cómo la informalidad surge a raíz de la inoperancia del estado al verse desbordado y no tener respuesta a las necesidades de un "nuevo" 
Perú, en el cuál la gran mayoría estaba sometida bajo un carácter de dominación, el sector "popular" o como ya lo mencionamos anteriormente, el Perú "real". Ante esto observamos la formación de dos circuitos económicos constituido por uno "formal" $\mathrm{u}$ "oficial" el cual consistía de un sector que se desarrollan en los sectores productivos y comerciales bajo el consenso y protección de leyes; y al mismo tiempo surge otro con un carácter contestatario y "popular", cuyo espacio de actividad se desarrolla a expensas de la legalidad, en sus fronteras o en los márgenes donde logran acomodarse en un nuevo medio bajo tácticas, maniobras, costumbres y hasta normas de la sociedad andina, desarrollando de esta manera sus propias reglas económicas particulares, en los lindeles de la legalidad y frecuentemente a espaldas del otro Perú "oficial".

Para ir finalizando es necesario mencionar del "nuevo rostro urbano" que Matos Mar menciona en su trabajo, este bajo el constructo o intento de una nueva identidad. Para 1980 las polis costeñas occidentales, o las grandes ciudades, sobre todo Lima sufrió una mutación importante, trajo consigo un incremento de la población urbana muy considerable. En Lima se puede hablar de la existencia de espacios urbanos muy marcados y distantes entre sí, no solo geográficamente, sino también y sobre todo culturalmente hablando; existe pues un espacio conformado por distritos tradicionales y modernos donde el Perú oficial se desarrolla con mayor naturalidad y hay otro espacio producto del surgimiento de urbanizaciones populares conocidas como "las barriadas", cuya resistencia como uno de sus factores acentúa el otro Perú, el "informal".

Surge aquí otro sujeto de estudio para las ciencias sociales, sobre todo la antropología, importante para el desarrollo del devenir histórico del Perú; el migrante, el marginado. Se desarrolla este nuevo actor social bajo los patrones, normas y reglas que el Perú oficial, formal impone. Este nuevo agente en este espacio formal urbano tendrá que adaptarse a las nuevas circunstancias que la ciudad le ofrezca y ante estas buscará posibilidades, soluciones y oportunidades bajo sus saberes tradicionales previos.

La migración como Matos Mar menciona compone y reconfigura las organizaciones sociales en la ciudad, los nuevos agentes migrantes arrastran su legado cultural hacia las ciudades gestando distintos fenómenos socio culturales que encuentra integración y/o resistencia como; las yunzas, carnavales, música andina, entre muchos más.

El desborde popular y la crisis del estado comienzan acentuarse en mayor medida y se genera un incesante colapso de los servicios públicos, entre otros como ya hemos mencionado. Mientras tanto Lima pugna por trazar un nuevo rostro, uno que resultará en gran medida por la oposición que genera la llegada de nuevos agentes sociales a un espacio urbano construido y dominado por un Perú oficial, criollo, cuya desgastada legitimidad generará resistencia a los migrantes andinos y a su inminente sincretismo socio cultural, originando nuevas instituciones basadas en tradiciones y saberes dotados de una orientación inherente de sus propias subjetividades, moral y hasta legal que resultan propias del uso cotidiano, costumbres, colectividades, que de las reglas impuestas por el Perú oficial.

Para finalizar es preciso mencionar que a través de estos desbordes sociales se configura una nueva organización social y surge, y consolida un nuevo agente social y político, quién sería el encargado de construir el devenir histórico del Perú y su nuevo rostro. Lima ya no es exclusivamente la ciudad capital urbana reducto de lo criollo y lo mestizo representada por el Perú formal o criollo monopolizando el poder y la identidad. Sin embargo, esta "nueva" nación para nuestro autor fue un fenómeno inconcluso, una deuda histórica que no se pagaba y que se repetía constantemente. El migrante de origen andino surgía, así como nuevo sujeto político para desarrollar las grandes transformaciones sociales incompletas que permitirían tener un nuevo rostro del Perú y terminar la tarea que la antigua república dejó pendiente y que el estado no ha podido resolver. 
Es imperativo terminar la reseña respondiendo la pregunta que nos planteamos al principio, este problema de la inoperancia estatal y de las grandes brechas de desigualdad responde a una problemática estructural que Matos Mar señala como la crisis del estado al visibilizar el encuentro de dos caras del Perú, tan distantes entre sí y no a una mera crisis coyuntural, sino que, a una cíclica, repetitiva que siempre vuelve y que sigue siendo postergada.

\section{Referencias Bibliográficas}

ALTAMIRANO, Teófilo (1979). Migración y Urbanización de Inmigrantes: Un Marco Conceptual Introductorio. Taller de Coyuntura Agraria, Lima: UNA

GOLTE, Jurgen (2001). Migración andina y cultura peruana. En: Cultura, racionalidad y migración andina (pp. 107 - 122), Lima: IEP

GOLTE Jurgen (2012). Capítulo 5: Migraciones o Movilidad Social Desterritorializada. En; No hay país más diverso: compendio de antropología peruana II (pp. 247-288). Lima: Instituto de Estudios Peruanos.

MATOS MAR, José (1986). Capítulo 1: Legado andino y patria criolla: Una nación inconclusa. En: DESBORDE POPULAR Y CRISIS DEL ESTADO, El nuevo rostro del Perú en la década de 1980 (pp. 23 - 40) (3era Ed.) Lima: IEP

MATOS MAR, José (1990). Las Migraciones campesinas y el proceso de urbanización del Perú. Lima: Un estudio encargado por la UNESCO

RODRIGUEZ V. Jorge (2004). Capítulos I - IV: En: Migración interna en América Latina y el Caribe: estudio regional del período 1980-2000 (pp. 9 - 39). Santiago: Centro Latinoamericano y caribeño de demografía (CELADE) 